\title{
PERFORMANCE EVALUATION OF 1 TBPS QPSK DWDM SYSTEM OVER ISOWC
}

\author{
Amandeep Singh ${ }^{1}$, Guneet Mander Uppal ${ }^{2}$ \\ ${ }^{1}$ Student, Department Of Electronics \& Communication Engineering, Chandigarh University, India \\ ${ }^{2}$ Asst Prof, Department Of Electronics \& Communication Engineering, Chandigarh University, India \\ Scholaramandeep@Gmail.Com
}

\begin{abstract}
Optical wireless communications has been in latest trends of high speed communications. They enable the use of optical wireless channel in applications like inter satellite links and underwater communications etc. In this paper, we communicate an ultra high bit rate i.e. 1 Tbps (10 x 100 Gbps) QPSK WDM System over optical Wireless communication Link. The system is a Line of Sight optical wireless link incorporating Coherent QPSK modulation Scheme forl0 channels each at 100 Gbps The performance is evaluated in terms of Q-Factor and Minimum Bit Error Rate which are noticed to be in acceptable standards. The Link is analyzed under various parameters such as Power, Distance etc and maximum achievable distance is noticed to be 50,000 km at power values ranging from $0 \mathrm{dBm}$ to $40 \mathrm{dBm}$.
\end{abstract}

Key Words- WDM, CO-QPSK, OWC

\section{INTRODUCTION}

Over the last two decades, wireless communications have undergone massive alterations and contributing remarkable alternatives for numerous high bandwidth and speed processing applications [1]. The next major step on stair towards these applications is realization of a network of optical wireless satellites. This optical satellite network can help in altering the complete scenario of space architecture as the optical wireless communications went through a huge expansion for its rewards over another competing techniques like RF. Firstly, the cost of deployment in case of optical communication systems decrements upto $10 \%$ as compared. Secondly, unlike millimeter-wave systems optical links can cover more distance in kilometers for which coventional systems required repeaters. Finally, an unlicensed spectrum of $\mathrm{THz}$ range can be used providing greater bandwidth and no additional inferences [3]. Verifications of command and control over pointing, acquisition ,tracking and telemetry have been made in literature [4]. These links offer higher bandwidth, tiny size, lesser weight, lower transmission power and low cost substitute to at hand microwave satellite systems [5] along with several benefits in weight diminution directly concerning to launch costs and fuel requirements [6].

In past, vast researches have been done and reported in which Inter Satellite Optical Wireless Communication Systems have been modelled [7] and the work includes various parameters that needs to be taken care of while designing optical wireless communication systems [8] such as effects of vibration[8] transmitted power [9], size of aperture of telescope [10]. Very high bit rate for OWC link have been achieved by $\mathrm{B}$. Patnaik et al in [11] and A Penchala Bindushree in [12] by selecting Quadrature Phase shift Keying (QPSK) as an optimum modulation scheme and maximum achievable distance is reported up to approximately $40,000 \mathrm{~km}$ at $5.6 \mathrm{Gbps}$ and $5,000 \mathrm{~km}$ at 438 Gbps.

In this paper we present a 10 x 100 Gbps QPSK modulated WDM system over Optical wireless communication Link and the system is analyzed for different Powers at different distances and aperture diameters of telescope measuring the performance in terms of Quality Factor and Bit Error Rate. The reported simulation is performed in Optiwave Optisystem Software which is a design suite for Optical Communication system design and analysis.

\section{SIMULATION SETUP}

The simulation setup of 10 channel QPSK WDM system over OWC link is described below in Figure 1. The bit rate at each channel is $100 \mathrm{Gbps}$ and system architecture is made by utilizing wavelength division multiplexing which is a promising technology in optical systems for capacity enhancement. The system comprises of three basic entities of a communication system i.e. Transmitter, Communication medium or channel and Receiver. These three have been discussed in detail in subsections. 


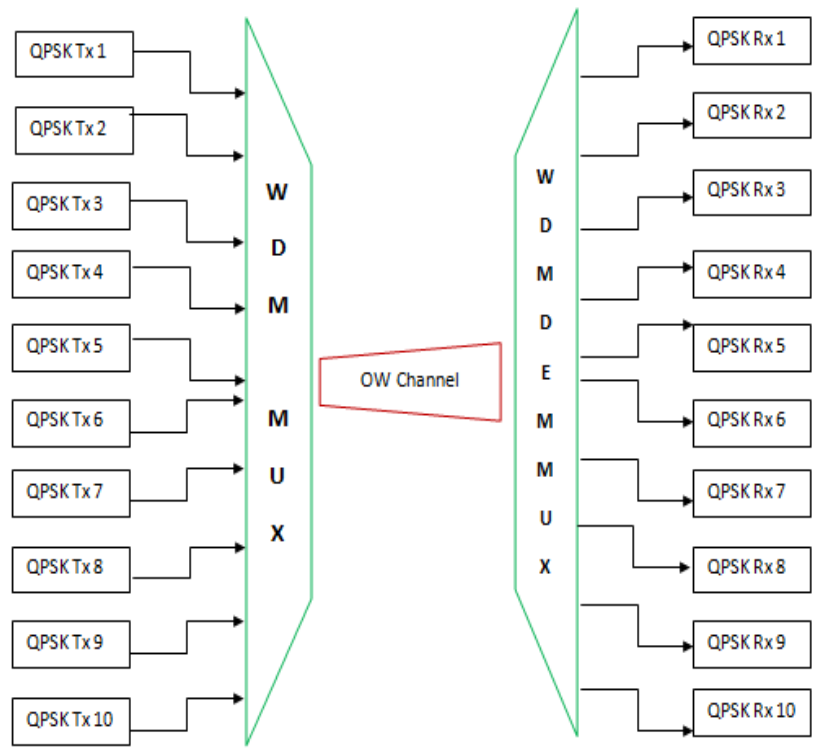

Figure 1- Block diagram of 10*100 Gbps QPSK WDM system over OW channel

\subsection{Transmitter}

The transmitter is a Coherent QPSK transmitter which generates the QPSK signal by using two Mach Zehnder modulators to encode QPSK symbols onto an optical carrier [12]. Each modulator modulates the in-phase (I) and Quadrature component (Q) of a carrier [11]. Number of bits per symbol is 2 . The PSK Sequence generator, which generates the in-phase (I ) and quadrature signals (Q) as given in (1) and (2), respectively [11]. The output of the PSK sequence generator is given to the M-array pulse generator, where $M \frac{1}{4} 4$. Using a coupler the optical signal is fed to the Mach-Zehnder (MZ) modulator and at the end both I and Q signals is combined using an optical power combiner as shown in Figure 2. The I and $\mathrm{Q}$ signals are given

$\mathrm{Ii}=\cos (\mathrm{fi})$

$\mathrm{Qi}=\cos (\mathrm{fi})$

Where wi 1/4 2p(i 2 1)/M, i 1/4 1, 2, 3, 4 and M 1/4 4 [11]

The two symmetrical arms in transmitter each consists of a Li-Nb Mach Zehnder dual arm modulator which is fed with electrical inputs after gain and biasing of an M-ary Pulse which gets its feed from a PSK Sequence generator. One of the modulated arms' phase is shifted and are collectively fed into a coupler which at output port provides Optical QPSK Signal.

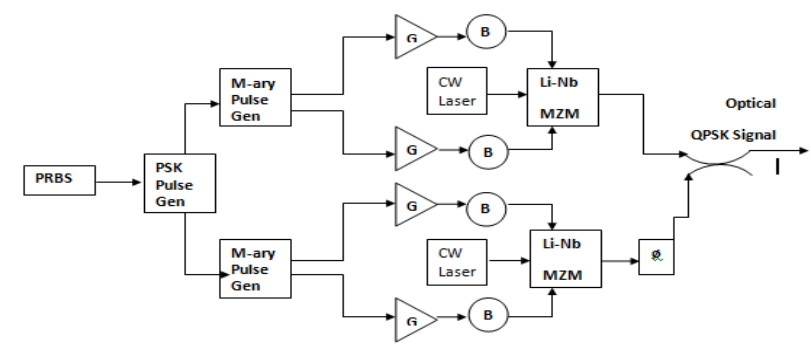

Figure 2- Coherent optical QPSK Transmitter

\subsection{Optical Wireless Channel}

The optical wireless channel characterized by following mathematical equation. The optical power at reception is given by

$\mathrm{P}_{\mathrm{R}=\mathrm{P}_{\mathrm{T}}} \eta_{\mathrm{T}} \eta_{\mathrm{R}}\left(\frac{\lambda}{4 \pi \cdot \mathrm{Z}}\right)_{\mathrm{G}_{\mathrm{T}} \mathrm{G}_{\mathrm{R}} \mathrm{L}_{\mathrm{T}} \mathrm{L}_{\mathrm{R}}}$

Where $\mathrm{P}_{\mathrm{T}}$ is optical power transmitted by transmitter; $\eta_{\mathrm{R}}$

and $\eta_{\mathrm{T}}$ are the optics efficiency of the receiver and transmitter respectively; $\lambda$ is the transmitted wavelength; $Z$ is the distance of optical wireless link; $\mathrm{G}_{\mathrm{T}}$ is the telescope gain of transmitter; $\mathrm{G}_{\mathrm{R}}$ is the receiver telescope gain; and $\mathrm{L}_{T}$, $\mathrm{L}_{\mathrm{R}}$ are the pointing loss factor of transmitter and the receiver, respectively.

\subsection{Coherent QPSK Receiver}

The coherent QPSK receiver consists of a photodetector which performs the optical to electrical conversion after which adequate DSP operations on signal as shown in figure are to be performed. The DSP for QPSK Block is shown in figure and it explains how signal processing operations such as DC blocking, Filtering, Resampling, time recovery, Adaptive equalizing etc are performed at signal. After this signal is fed into decision component which processes the I and Q signals from DSP block. The thresholds are now decided and I and Q signals are put into PSK Sequence decoder at which we visualize the output signal using BER test set in terms of Q factor and Bit error Rate.

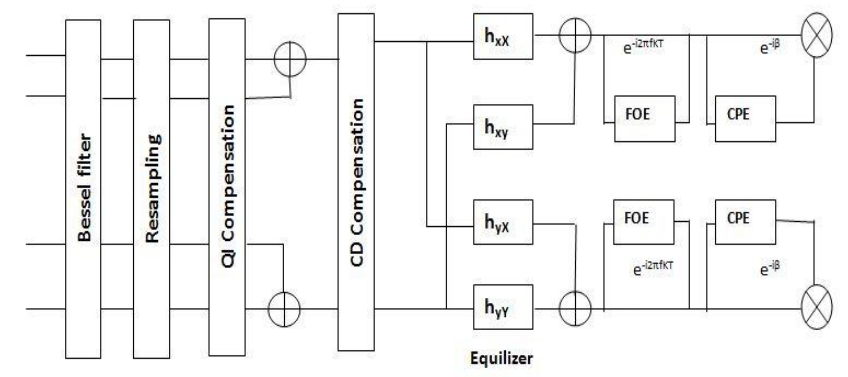

Figure 3- DSP in Receiver for QPSK [13]

\section{RESULTS AND DISCUSSION}

The system is simulated at 1 Tbps (10 channels with 100 Gbps at each channel). The output is visualized by using BER Test Set in terms of Quality factor of received signal and bit error rate and is found to be in acceptable limits.

Table 1 shows the $\mathrm{Q}$ factor and minimum BER obtained at distance varying from $10,000 \mathrm{~km}$ to $50,000 \mathrm{~km}$.

Table 1- Q-factor and Min BER at varied range of OW channel

\begin{tabular}{|l|l|l|}
\hline Distance in Km & Q-factor & BER \\
\hline 10,000 & 8.12 & $0.432 \mathrm{e}-15$ \\
\hline 20,000 & 7.94 & $1.83 \mathrm{e}-15$ \\
\hline 30,000 & 7.60 & $28 \mathrm{e}-15$ \\
\hline 40,000 & 7.27 & $0.33 \mathrm{e}-12$ \\
\hline 50,000 & 6.87 & $6.11 \mathrm{e}-12$ \\
\hline
\end{tabular}


Figure 4 shows graph of Distance vs. Q-factor from which it can be concluded that $\mathrm{Q}$ factor goes on decreasing as we move forward in terms of distance.

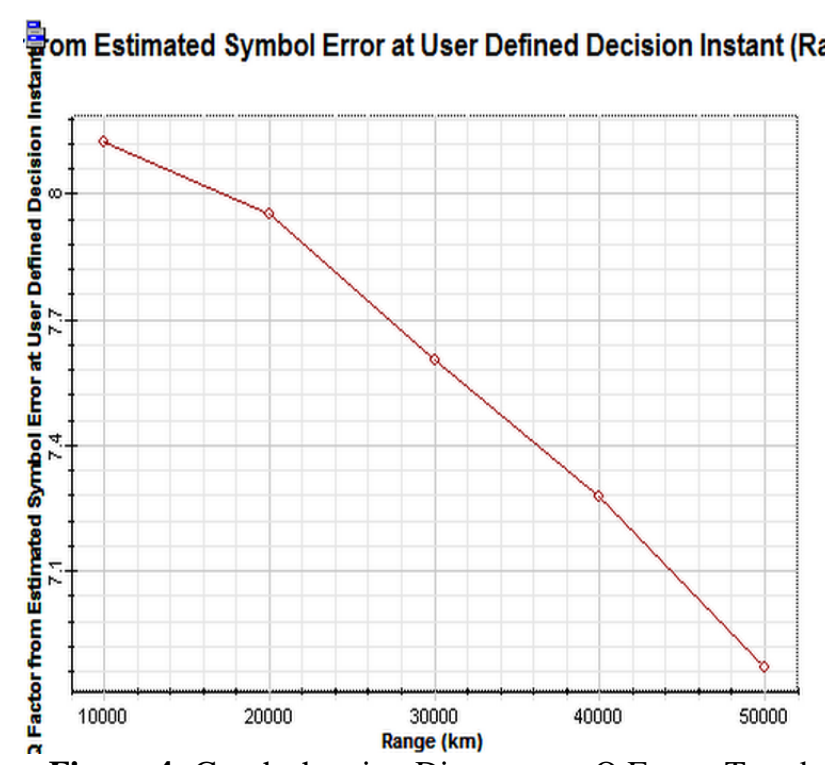

Figure 4- Graph showing Distance vs. Q Factor Trends

Figure 5 shows graph of Distance vs. log BER and shows that error rate increases as the range of optical wireless channel is increased.

\section{氶mated Symbol Error at User Defined Decision Instant (Range (km)}

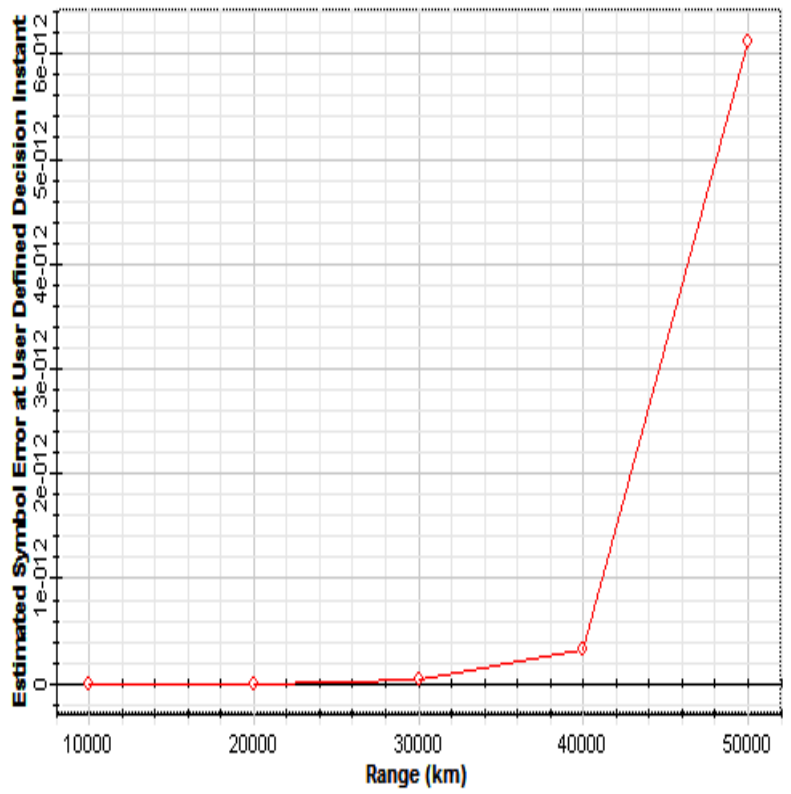

Figure5- Graph showing Range vs. BER

The Constellation diagrams of received signals at various distances are shown in Figure 6 and 7 and it becomes clear from visualization geometry that constellation gets distorted which shows the addition of noise with distance.

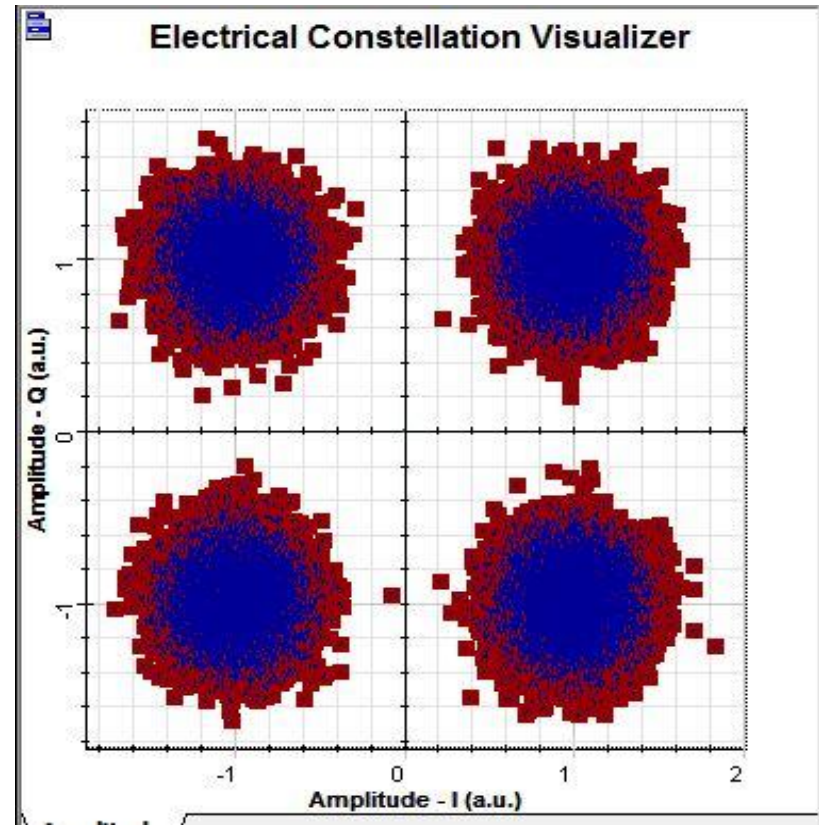

Figure 6- Electrical constellation diagram at $10000 \mathrm{~km}$
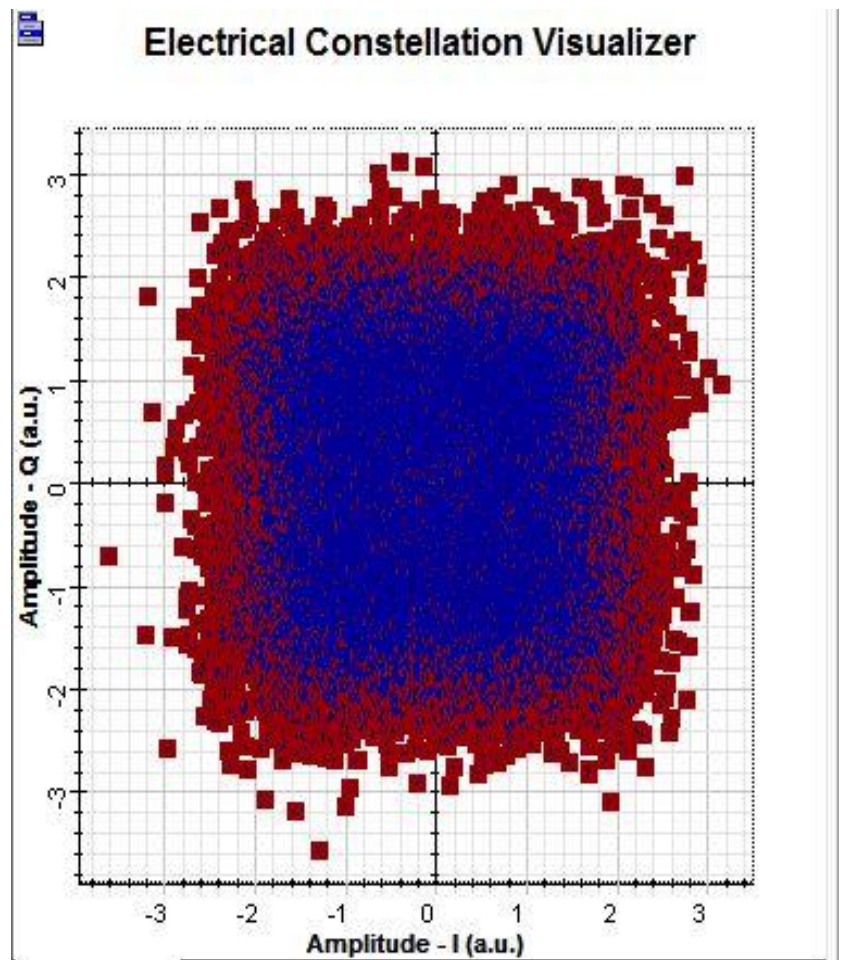

Figure 7- Electrical constellation Diagram at 50,000 km

The Constellation diagrams of received signals at minimum and max power iterations are shown in figure are shown in Figure 8 and 9 and it can be derived that the signal improves as the transmitted Power of system is increased but in case of power it is the non-linear effects and other issues like inter channel crosstalk that are to be taken into account while designing high power systems. 


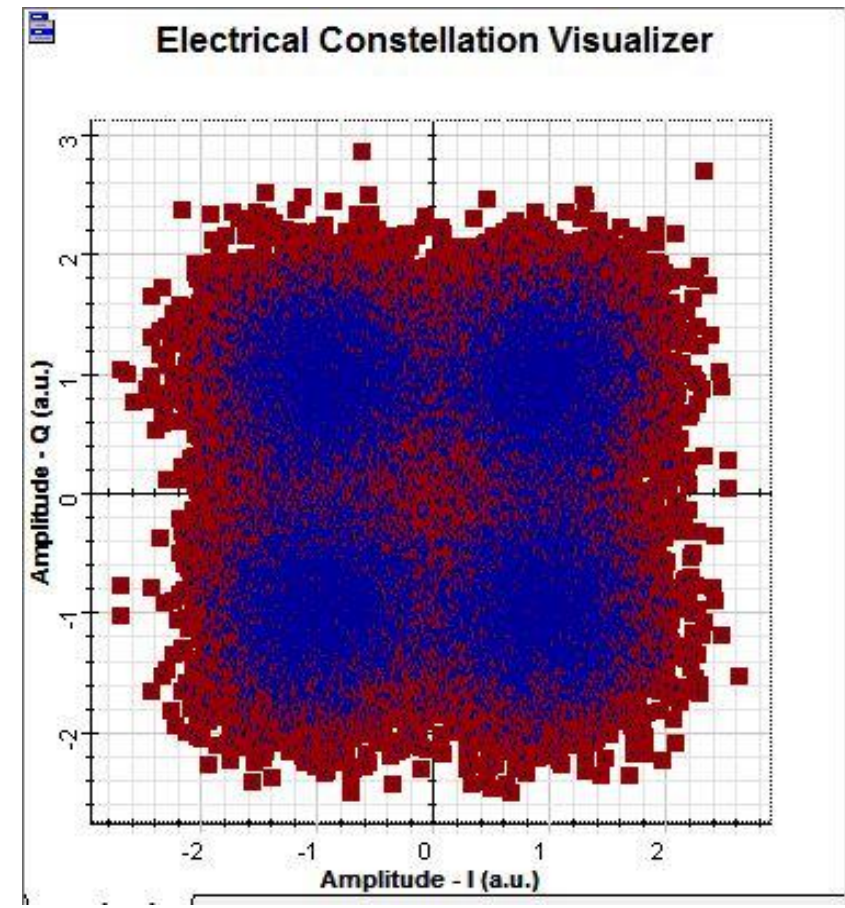

Figure 8- Electrical constellation diagram at 0dBm Power

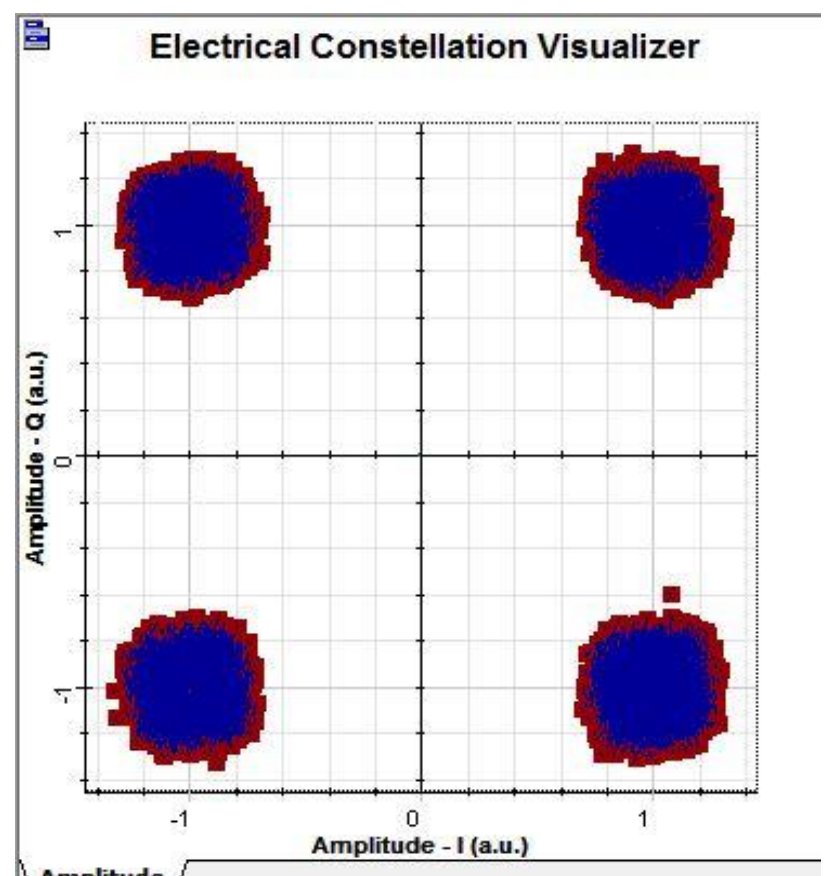

Figure 7- Electrical constellation Diagram at $40 \mathrm{dBm}$ Power

Similarly Figure 10 and 11 shows the Input Power vs. Qfactor and BER respectively and it can be seen that Q-factor increases and Bit Error rate decreases as the transmitted power is increased. Power is varied from $0 \mathrm{dBm}$ to $40 \mathrm{dBm}$

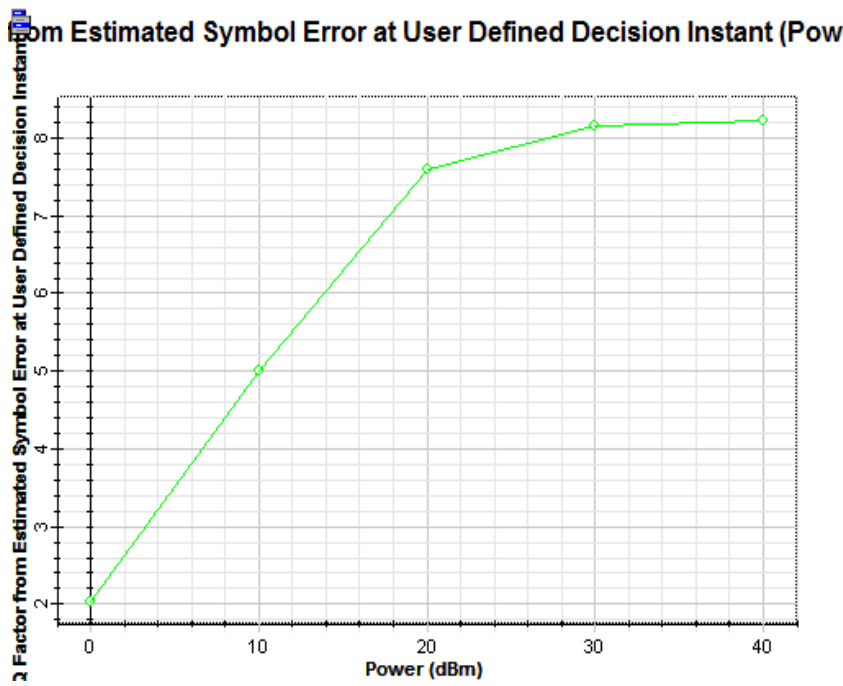

Figure 10- Trends in Q-Factor when power is varied from 0 to $40 \mathrm{dBm}$

\section{党stimated Symbol Error at User Defined Decision Instant (Power (dl}

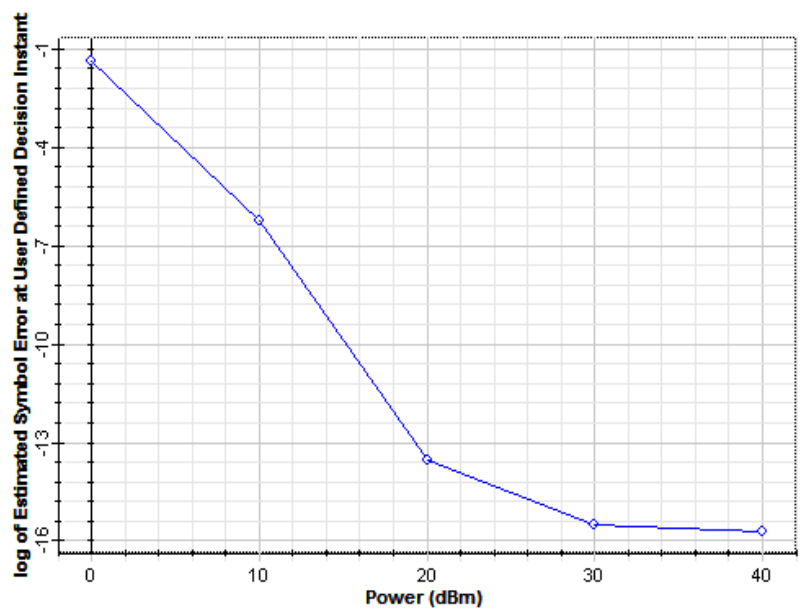

Figure 11- Plot of Power vs. log BER

\section{CONCLUSION}

From the reported work on CO-QPSK-WDM-OWC system on 1 Tbps the findings on Q-Factor and BER are under acceptable limits and system is found to travel up to 50,000 $\mathrm{Km}$ at $100 \mathrm{Gbps}$ data rate on each channel. The power of system is varied from $0 \mathrm{dBm}$ to $40 \mathrm{dBm}$ and an ascending trend in $\mathrm{Q}$ factor has been observed. Similarly the Distance is iterated for various values and respective electrical constellations have been seen proving that noise distorts the signal as the link distance is increased up to $50000 \mathrm{~km}$.

\section{REFERENCES}

[1]. Arnon S., Karagiannidis George K., Barry, John R. Schober, Robert, Uysal,Murat" Guest Editorial Optical Wireless Communications", IEEE, vol. 27, no. 9, December 2009.

[2]. Vincent W. S. Chan,"Optical Satellite Networks" Journal of Lightwave Technology, vol. 21, no. 11, November 2003

[3]. Juan-de-Dios, Arturo Arvizu M, Francisco J. Mendieta and et al ,"Trends of the Optical Wireless 
Communications", Advanced Trends in Wireless Communications, Dr. Mutamed Khatib ISBN: 978953-307-183-1,

[4]. Heine, F., Kampfner, H., Lange, R., Czichy, R., Meyer, R. and Lutzer, M. (2010) "Optical Intersatellite Communication Operational" IEEE, Military Communications Conference,pp. 2284-2288.

[5]. Krainak, M. A., (1992) "Intersatellite Communications Optoelectronics Research at the Goddard Space Flight Center" IEEE-AES Systems Magazine, pp. 44-47.

[6]. Arruego, H. Guerrero, S. Rodriguez, J. Martınez-Oter, J. J. Jimenez, J. A. Dominguez, A. Martın Ortega, J. R de Mingo, J. Rivas, V. Apestigue, J. Sanchez, J. Iglesias, M. T. A lvarez, P. Gallego, J. Azcue, C. Ruiz de Galarreta, B. Martın, A. A lvarez Herrero, M. DiazMichelena, I. Martın, F. R. Tamayo, M. Reina, M. J. Gutierrez, L. Sabau, J. Torres," OWLS: A Ten-Year History in Optical Wireless Links for Intra-Satellite Communications", IEEE Journal of selected areas, vol. 27, no. 9, December 2009

[7]. Hashim, A. H., Mahad, F. D., Idrus, S. M. and Supaat, A. S. M."Modeling and Performance Study of InterSatellite Optical Wireless Communication System" Proceeding of International Conference on Photonics, Langkawi, Kedah, pp. 1-4.

[8]. Rani, M. and Prince, S. (2012) "A Study on Intersatellite Optical Wireless Communication and Its Performance Analysis" International Conference on devices circuits and systems (ICDCS-2012), Coimbatore, pp 202-205.

[9]. Singh, Kuldeepak. and Bhamrah, Manjit .S," Investigations of Transmitted Power in Intersatellite Optical Wireless Communication", International Journal of Computer Science and Information Technology \& Security Vol. 2, No.3, June 2012

[10]. Singh, K. and Bhamrah, M. S "Investigations on Aperture Diameter of Telescope in Intersatellite Optical Wireless communication system" International Journal of Engineering Research and Applications, Vol. 2, Issue 3, pp. 1666-1670

[11]. Ciaramella, E., Arimoto, Y., Contestabile, G., Presi, M., D'Errico, A., Guarino, V. and Matsumoto, M. (2009) "1.28 Terabit/s (32x40 Gbit/s) WDM Transmission System for Free Space Optical Communications" IEEE, Vol. 27, No.9, pp. 1639-1645.

[12]. Patnaik, B. and Sahu, P.K. "Design and Study of High Bit-Rate Free-Space Optical Communication System Employing QPSK Modulation, International Journal of Signal and Imaging Systems Engineering, Vol. 6, No. 1, pp. 3-8.

[13]. A Penchala Bindushree, Vijesh T V, Laxmiprasad A S,"Design And Simulation Of QPSK Modulator For Optic Inter Satellite Communication", International journal of scientific \& technology research volume 3, issue 8, August 2014 